\title{
Performance Evaluation of Adopting the Electronic Style in Hospital Services
}

\author{
Juliana Iworikumo Consul, Niger Delta University, Nigeria \\ Bunakiye Richard Japheth, Niger Delta University, Nigeria \\ Joseph Agaroghenefuoma Erho, Niger Delta University, Nigeria \\ iD https://orcid.org/0000-0003-2857-0462
}

\begin{abstract}
Globally, health information systems and technologies are being used increasingly and are seen as a way to increase the efficiency and quality of patient care. One of the factors blocking the use of electronic healthcare system from widespread acceptance as experienced in the manual method is the concern about patients' data confidentiality. This paper is set to discuss and appraise the adoption of electronic style in the provision and management of hospital services for efficiency, accuracy, and timely delivery of services in order to enhance the data confidentiality. Data collected from questionnaire were analysed and evaluated based on two identified significant aspects: the problems of either adopting the electronic healthcare or manual system of keeping patient information and the efficiency, problems, and barriers of adopting the electronic healthcare style in hospitals. It is observed that the adoption of electronic style will improve interactivity in all areas of specialization in hospital management.
\end{abstract}

\section{KEYWORDS}

Data Analysis, E-Healthcare, Electronic Health Records (EHRs), Electronic Medical Record (EMR), Information Technology (IT), Medical Personnel

\section{INTRODUCTION}

Information technology (IT) is emerging in health care in the form of electronic healthcare (e-healthcare) with the introduction of modern health care facilities (Aceto et al., 2018). Some research at the individual level has found that doctors have typically not embraced e-healthcare systems very effectively and rather prefer to use paper records (Williams, 2018). E-healthcare is important because firm-level benefits are ultimately garnered when individuals in critical roles in healthcare organizations embrace and use implemented systems (Venkatesh, et.al., 2011) and (Loo et al., 2020). If such uses occur, invariably, it could lead to positive outcomes (Lichtner et al., 2020). There has also been work on user acceptance and usability, for example, by bringing people together, information technologies have the potential to improve both the quality of and access to health care in the remotest areas of the developing world (Mitchell and Kan, 2019).

\section{DOI: 10.4018/IJARPHM.20210701.oa1}

This article published as an Open Access article distributed under the terms of the Creative Commons Attribution License (http://creativecommons.org/licenses/by/4.0/) which permits unrestricted use, distribution, and production in any medium, provided the author of the original work and original publication source are properly credited. 
In most of the hospitals or health centres in developing economies, electronic communication between patients and all interface of the hospital is not typically employed but, rather, the patients still does the moving around (Alotaibi and Federico, 2017). Metahri et al., (2020) also added voice to the credibility of an automated system for healthcare delivery by presenting a performance comparison of manual dispensing and automated drug delivery. To improve this process, communication should be done electronically from different phases (Rotenstein et al., 2017). E-healthcare systems are software modules set to meet the health needs of target populations (Alrasheed et al., 2016). In some certain administration and countries healthcare planning is dispensed among market attendant (Land and Trudy, 2019), whereas in some, planning occurs more centrally among governments or other team up bodies through the adoption of such modules (Parsons and James, 2019).

Advances in e-healthcare technology over the last few decades have improved the delivery of health care and significantly improved life expectancy (Rotenstein et al., 2017). It is a fast emerging area, where medical informatics, communal healthcare, health service providers and the information through Internet and its related information and communication technologies cooperate strongly to achieve uniformity in dispensing good health care (Aceto et al., 2018). Recent research on the development and use of information and communication technology (ICT) has focused on the emergent use of technology in practice and the multiplicity of outcomes being simultaneously negotiated by different groups and individuals (Chung et al., 2018). In working in tandem with known scholars (Wang, 2020), this paper is set to raise some pertinent questions about how e-health facilities are adopted and used, and in addition answers to these questions are sought to ensure that the problems of manual adoption to the provision of hospital services are clearly highlighted and solutions proffered.

The remaining sections are organized as follows. Section 2 discusses background on challenges associated with managing patients' records manually, the process of the electronic health records management and related literature. Section 3 presents the context in which the work was developed. Section 4 describes the user interaction process with a potential e-healthcare system. Section 5 itemises the data collection and analysis requirements, which discussed the performance evaluation metrics that addressed the benefits of accepting the electronic style in hospital services. Section 6 concludes the paper.

\section{RELATED LITERATURE}

One of the features of electronic healthcare system is patient management. For this simple fact, electronic health records (EHRs) have become standards for care, medication safety and duty bound implementation by medical professionals. In a number of examples cited by Whalen (2018), after implementation, there was a tremendous increase in the overall number of medication safety reports involving doses and dosing volumes, productivity in service for ordering clinicians, and standardized safeguard procedures. However, Whalen (2018) revealed that there were reported cases of medication error rates for specific application areas in neonatal and pediatric subsets spanned through a period of time, which further stressed the point that, there is need to be focused on standards and guidelines on implementing electronic health records that encompasses all age context. This work is therefore contingent on this need to ensure error free interactivity across the various duties that can possibly be offered in a hospital.

Kruse et al., (2018) discussed that in some instances, electronic health records being the core of adopting e-health services in hospitals have also shown lack of interoperability, functionality and medical errors. Kruse et al., (2018) further stated that, even though a few errors may occur, electronic health records are being commonly used and provide many benefits. They have emerged to improve the quality and efficiency of healthcare, and health disparities in population health. The primary objective to ensure that there is widespread availability of electronic health records with the full promised benefits of utilization was presented by Reisman (2017) and as well, some challenges of managing patient records as closely linked to the abuse of patient information was also identified. 
Subsequently, Kruse et al., (2018) did assess the relationship of electronic health records use through the identification and analysis of facilitators and barriers to its adoption. They were also able to identify more facilitators than barriers to the use of electronic health records to support public health. In this current paper, the consideration is centred on the utilization of e-health facility in such a way that errors can easily be identified and corrected among professionals since the abuse of patient information may be eliminated or drastically reduced across the communication paths.

Many factors affect the performance of appointment systems including arrival and service time variability, patient and provider preferences, available information technology and the experience level of the scheduling staff (Ratwani et al., 2018). Therefore, in terms of quality consideration, firstly, an electronic patient record improves the quality of healthcare and access to information. Secondly, it reduces clinical errors often attributed to illegible physician's handwriting. Electronic patient records may also contribute to cost reduction measures in the management of patient records (Reis et al., 2017). Accordingly, Dwenger et al., (2019) also stressed the usefulness of electronic health records to improve information sharing by health practitioners thus enhancing communication of patient information. This idea from Dwenger et al., (2019) compliments the theoretical context of this paper, where adopting the electronic style in hospital services should promote valid information sharing among all areas of specialization in hospital management. Adopting Big data in healthcare management, Dash et al., (2019) posited that archiving digital data is a real time, digital versioning of patient-centred records that make information available instantly and securely to authorized users. This assertion is an advantage in this context because big data analytics procedures and process implementation, especially in hospital services provide massive amounts of information that can improve the services they provide.

Electronic health records go beyond the data collected in the provider's office and include a more comprehensive patient history (Han et al., 2016). Electronic health record systems, Evans (2016), are designed to store data accurately and capture the state of a patient across time. Liu et al., (2020) further expressed the resilience of the health professional in handling electronic health records amidst any challenges so that the necessary interactions needed to bringing the expected outcomes can be achieved. For effective utilization by health professionals, Sanam (2020) identified the factors that influence the manner by which physicians use electronic health records with patients. It eliminates the need to track down a patient's previous paper medical records and assists in ensuring data is accurate and legible. It can reduce risk of data replication as there is only one modifiable file, which means the file is more likely to be up to date and decreases risk of lost paperwork. Accordingly, Sanam (2020) stated that since hospitals are the main healthcare providers in developing countries, the underlying health system quality must be carefully considered and included in the design and delivery of services. It is therefore essential that an electronic healthcare system be placed in hospitals that can manage all the information to allow health care providers to do their jobs effectively. This is because the application addresses the needs of various departments in a hospital. They manage the data related to the clinic, finance department, laboratory, nursing, pharmacy, and radiology and pathology departments. To achieve all of this success, a critical feature to be found in an e-healthcare system is that health information has to be created and managed by authorized providers in a digital format capable of being shared with other providers across more than one health care organization (Schopf et al., 2019). Sieck et al. (2020) also added that physicians sometimes limit themselves because they fail to utilize to a logical conclusion all the perspectives of electronic healthcare systems. In addition, Sieck et al. (2020) mentioned that health professionals also exhibit reluctance to accessing such systems. A limiting factor in realizing the full potential of electronic medical records is the health service providers' reluctance to use these systems. Therefore, the main idea presented in this paper is the reduction in the reluctance of the utilization of e-health services and the increase in productivity in health services in all areas of specialization in hospital management through the adoption of e-healthcare in hospital services. 


\section{PROPOSED PROCESS FLOW}

The process flow involves a linear deployment approach which has to do with an organized structure, the involvement of medical personnel with the collection instruments and the medical personnel involvement with the system that will improve the overall quality of healthcare delivery in hospitals.

\subsection{Linear Deployment Approach}

This section presents the background to which the user interaction process with a potential e-healthcare system is described that subsequently lead to the appraisal of the electronic style in hospital services (Ross et al., 2016) and (Boonstra et al., 2014). The electronic style for hospital services provision through a potential e-healthcare system is seen to be possible through a well-defined requirement specification that moves through to deployment in a linear form. Each health information system has, at the minimum, some sort of information generating processes whereby data are transformed into information. In order to run this process, a more or less organized structure is accessible where medical personnel interact with resources, such as data collection instruments for data organization and analysis, or with machines, such as computer hardware and software interfaces for implementing the analyzed data.

\subsection{Medical Personnel Involvement With the Collection Instruments}

Basically, the data collection instrument will be in the style of a soft copy form. Definitely, each of these forms will have the functionality of collecting specific data from the doctors, staff and patients (Sarkies et al., 2015) as the case may be. Accordingly, the form will have specific details to capture patient's data, doctor's data, laboratory scientist data, nurse's data, pharmacist data and receptionist data for the sole intention of adopting the electronic health record facility.

The portfolio usually is an electronic tool that is designed for the professionals such as doctors, pulmonologist, haematologist, oncologist, gynaecologists, and nurses amongst others to store and record a proof that exhibit their learning achievements and abilities (Ondieki, 2017). Traditionally, the medical history of a patient is the information gained by any of the mentioned specialist through asking specific questions, either of the patient or of other people who knew the person and can give suitable information (Kelly \& Brandon, 2013). The major objective of this design is to provide necessary control to both manual and automated system so as to help maintain the integrity of the data base files and by extension to achieve a new system that is more reliable and robust than the working principle of a static hospital.

\subsection{Medical Personnel Involvement With the System}

A Health official in the hospital has to have knowledgeable access to the e-health technology applications that are essential tools for the implementation of the demands from patients. The indication is that modern information technology that improve quality of healthcare delivery in hospitals have to play in such a way that medical personnel are now fully involved with the sole responsibilities for improvement in health care delivery (Alotaibi \& Federico, 2017). This collaborative tendency breeds positive benefits, in e-health adoption in hospital administration. This is due in part, to breaking of barriers such as resistance from healthcare professionals, poor infrastructure, and low technical expertise among others. The results obtained from the consistent involvement, which correspond with inputs from the data collection instruments, indicate that perceived usefulness, belief, willingness, as well as attitude of healthcare professionals have significant influence on their intention to adopt and use the e-health technology applications. 


\section{THE CONCEPTUAL RELATIONSHIP}

The conceptual relationship simply depicts the complete working cycle of a typical e-health system that provides the needed services in a hospital. It typically involves first level interactions of the user with the system through the interface, a second level interaction that has to do with user authentication and the input process management where display of results of the user interaction with the system is achieved.

\subsection{First Level Interactive Relationship}

Typical e-health systems display at the software interface module the capability to register patients and medical personnel with unique numbers so that the user login details can be created. With this number assigned during design at the database logic, the medical history and bio data of the user can then be generated. Relatively, the main aim is that the system can assist health professionals to perform at optimal in their various specializations. For example, in taking patients preliminary examination, accessing current health condition, managing appointment queue and waiting list etc. (Mardiah \& Basri, 2013). Preliminary examination as a collection instrument involves taking temperature reading, blood pressure, height and weight of the patient.

\subsection{Second Level Interactive Relationship}

The second level interactive relationship for the user is usually to login into the system with the specified login details, which is necessary to bring to bear the interactive interface where automated feedback can be achieved after user query resource is input. This approach makes full use of the program flow in a class hierarchy as suggested in the proposed process flow of the system (Mohd \& Muhammad, 2012). This is made possible because the system structure had earlier defined from the interface which parts of an object the user can interact with through the communication path to effect a feedback. For the feedback to take effect, knowledge is represented through the data entities that are made available from the collection instruments.

Such denotations in the knowledge representation include ward, patient, doctor, team, consultant doctor, junior doctor etc. Accordingly, the attributes related to the denotations, which are actually the well-defined requirement specification of the system are as follows:

Ward: name, type, capacity, number-of-Bed (System domain)

Patient: name, sex, date-of-Birth, age (System domain)

Team: code (System domain)

Doctor: name (System domain)

Junior Doctor: name, grade (use case)

Consultant Doctor: name (use case)

Having identified the system requirements and attributes, their formal descriptions in line with the conceptual relationship model are described in Table 1.

The system is solely intended for hospital staff to register doctors, employee and patients where all must be affiliated with an identity number before sending it to the database. The attributes in the specified system are the user tables in the form of records in the database management system (DBMS) (Iroju \& Olaleke, 2015). The tables in the system are capable of accommodating the records of individual hospital staff and patients categorized to fill up personal data in order for personnel in such categories to be able to register through the e-health system for proper data management. This explains the usable profile of the features of system where the logic indicates that various kinds of menus in the program are coordinated for easy accessibility so that users can access the system. Once 
Table 1. Requirement attributes description

\begin{tabular}{|c|c|c|}
\hline System Template & Argument Attributes & Attribute Description \\
\hline \multirow[t]{5}{*}{ Class } & ward & A ward in the hospital \\
\hline & name & The unique name of the ward \\
\hline & type & Male or female patients ward \\
\hline & capacity & Number of patients on the ward \\
\hline & number of bed & Number of free beds on the ward \\
\hline \multirow[t]{5}{*}{ Class } & patient & A patient in the hospital \\
\hline & name & The name of the patient \\
\hline & $\operatorname{sex}$ & The sex (M or F) of the patient \\
\hline & Date of birth & The date of birth of the patient \\
\hline & age & The age of the patient in years \\
\hline \multirow[t]{2}{*}{ Class } & team & A team of doctors \\
\hline & code & The unique code of the team \\
\hline \multirow[t]{2}{*}{ Class } & doctor & A doctor at the hospital \\
\hline & name & The name of the doctor \\
\hline \multirow[t]{3}{*}{ Class } & juniordoctor & A junior doctor at the hospital \\
\hline & name & The name of the junior doctor \\
\hline & grade & The grade $(1,2$ or 3$)$ of the junior doctor \\
\hline Class & consultant_doctor & A consultant doctor at the hospital \\
\hline
\end{tabular}

the features are displayed, it then becomes a confirmation of complete access to all files and data corresponding to the category of the user accessing the system. The working procedure description will then necessitate that medical professionals' details can be added and viewed, patient details can be added and viewed, reservation details can be added and viewed, employee details can be added and viewed, and payments made and viewed.

\subsection{Input Process Management}

The input process depicts data captured into the system through forms. For example, the patient check-up form is a function of the hospital management (Pardamean et al., 2012). It generates a check-up identity number automatically when a patient clicks on add to register for check-up, which saves it in the database. The laboratory test reservation form registers the patients for laboratory test depending on their cases (Panos \& Michael, 2006). The patient after seeing a doctor might be requested to do a laboratory test to further aid treatment. The doctors and nurses form are primarily used by the hospital management to add doctors and nurses that are employed with the hospital and can accept patients for proper treatment and admission. There is provision made for personal details of the doctors and nurses and specialization before saving to the database logic as earlier stated. In the system, the user page usually displays all the users and their personal medical and bio data details. The other nonprofessional medical staff data are as well captured in the database to ensure accessibility. (Venkatesh et al., 2011). However, the system administrator has the privilege to add patients, doctor, nurses and other users that interface with the system. 
Table 2. Demographic data of the respondents by profession, sec, and age

\begin{tabular}{|c|c|c|c|c|c|c|c|c|}
\hline \multirow[t]{3}{*}{ Profession } & \multicolumn{8}{|c|}{ Sex } \\
\hline & \multicolumn{4}{|c|}{ Female } & \multicolumn{4}{|c|}{ Male } \\
\hline & $\begin{array}{c}21- \\
30 y r s\end{array}$ & $\begin{array}{c}31- \\
40 y r s\end{array}$ & $\begin{array}{c}41- \\
50 y r s\end{array}$ & $\begin{array}{c}\text { 51yrs and } \\
\text { Above }\end{array}$ & $\begin{array}{c}21- \\
30 y r s\end{array}$ & $\begin{array}{c}31- \\
40 y r s\end{array}$ & $\begin{array}{c}41- \\
50 y r s\end{array}$ & $\begin{array}{c}51 y r s \text { and } \\
\text { Above }\end{array}$ \\
\hline Doctor & 0 & 4 & 5 & 2 & 0 & 8 & 5 & 6 \\
\hline Lab. Scientist & 2 & 8 & 5 & 2 & 3 & 3 & 3 & 4 \\
\hline Nurse & 2 & 17 & 7 & 3 & 0 & 0 & 0 & 1 \\
\hline Pharmacist & 1 & 7 & 5 & 0 & 3 & 7 & 1 & 6 \\
\hline Receptionist & 2 & 15 & 5 & 1 & 0 & 2 & 3 & 2 \\
\hline
\end{tabular}

\section{THE EVALUATION METRICS}

\subsection{Data Collection and Analysis}

For the purpose of data collection and analysis, primary data was collected through questionnaires which were administered to the staff of different hospitals which have either adopted the electronic healthcare style of hospital management or the manual method of keeping patient information. One hundred and fifty respondents were selected on the basis of simple random sampling (Nduka, 2015) from selected hospitals in Yenagoa of Bayelsa State of Nigeria in West Africa. The division of the data collection was made on the basis of 75 respondents from hospitals which have adopted the electronic healthcare style (EHS) and 75 respondents from hospitals using the manual method of keeping patient records. The respondents in each of these two groups were further divided into five categories according to their professions. The professions include Doctors, Nurses, Laboratory Scientist, Pharmacist and Receptionist. The sections discussed in the questionnaire include: the problems of either adopting the electronic healthcare system or manual methods of keeping patient information and the efficiency, problems and barriers specific to adopting the electronic healthcare system in the hospitals. The data will be extracted from the questionnaires and the necessary information will be compiled using $\mathrm{R}$ Statistical Software (R Development Core Team). The data collected will be analyzed using some statistical tools such as the measures of central tendency and Chi square test (Nduka, 2015) to find out the inferences of the research.

The demographic data of the respondents by professions, sex and age are presented in Table 2 .

From the demographic data shown in Table 2, 19 (63.3\%) of the Doctors were male and 11 (36.7\%) were female doctors. Seventeen $(56.7 \%)$ of the Laboratory Scientist were female and 13 (43.3\%) were male. Nearly all, $29(96.7 \%)$ of the Nurses were female and only $1(3.3 \%)$ was a male Nurse. Seventeen (56.7\%) of the Pharmacist were male and the remaining 13 (43.3\%) were female. Twenty three (76.7\%) of the Receptionist were female and the remaining 7 (23.3\%) were male.

Twelve (40\%) of Doctors, 11 (36.7\%) of the Laboratory Scientist, 17 (56.7\%) of the Nurses, 14 (46.7\%) of the Pharmacist and $17(56.7 \%)$ of the Receptionist fall within the age group of 31 to 40 years. There were very few of the professionals that fall within the ages of 21 to 30 years. None of the Doctors were of ages 21 to 30 years.

\subsection{Analysis to Summary of Responses to Computer Literacy}

In this section, questions on the level of computer literacy of professionals will be analyzed. The summary of the responses to the question on computer literacy are presented in Table 3.

From Table 3, the summary of responses from the professionals showed that all professionals that work in hospitals that have adopted the electronic healthcare system are all computer literate. It 
Table 3. Summary of Responses to Computer Literacy by Professions and Method of Keeping Patient Records

\begin{tabular}{|c|c|c|c|c|}
\hline Profession & Response & Manual Method (\%) & EHS (\%) & All \\
\hline \multirow[t]{3}{*}{ Doctor } & Yes & $15(100)$ & $15(100)$ & $30(100)$ \\
\hline & No & $0(0)$ & $0(0)$ & $0(0)$ \\
\hline & Total & $15(100)$ & $15(100)$ & $30(100)$ \\
\hline \multirow[t]{2}{*}{ Lab. Scientist } & $\begin{array}{l}\text { Yes } \\
\text { No }\end{array}$ & $\begin{array}{l}10(66.7) \\
5(33.3)\end{array}$ & $\begin{array}{l}15(100) \\
0(0)\end{array}$ & $\begin{array}{l}30(100) \\
0(0)\end{array}$ \\
\hline & Total & $15(100)$ & $15(100)$ & $30(100)$ \\
\hline \multirow[t]{3}{*}{ Nurse } & Yes & $6(40)$ & $15(100)$ & $21(70)$ \\
\hline & No & $9(60)$ & $0(0)$ & $9(30)$ \\
\hline & Total & $15(100)$ & $15(100)$ & $30(100)$ \\
\hline \multirow[t]{3}{*}{ Pharmacist } & Yes & $8(53.3)$ & $15(100)$ & 23 (76.6) \\
\hline & No & $7(46.7)$ & $0(0)$ & $7(23.3)$ \\
\hline & Total & $15(100)$ & $15(100)$ & $30(100)$ \\
\hline \multirow[t]{3}{*}{ Receptionist } & Yes & $9(60)$ & $15(100)$ & $24(80)$ \\
\hline & No & $6(40)$ & $0(0)$ & $6(20)$ \\
\hline & Total & $15(100)$ & $15(100)$ & $30(100)$ \\
\hline
\end{tabular}

is also obvious that all Doctors that work in hospitals that use the manual method of keeping patients records are computer literate. More of the Laboratory Scientist 10 (66.7\%), Pharmacist 8 (53.3\%) and Receptionist $9(60 \%)$ that work in hospitals that use the manual method of keeping patient records are computer literate. Only 6 (40\%) of the Nurses that work in hospitals that use the manual method of keeping records are computer literate. In total, professionals that work in hospitals that have adopted the electronic healthcare system are highly computer literate than those that work in hospitals that use the manual method of keeping records (100\% versus $64 \%)$. This can be justified by using the Chi-squared test. The null hypothesis $\mathrm{H}_{01}$ is therefore formulated as follows:

$\mathbf{H}_{\mathbf{0}}$ : There is no significant difference in the level of computer literacy among professionals working in hospitals that have adopted the electronic healthcare system and those that work in hospitals that use the manual method of keeping records.

The alternative hypothesis $\mathrm{H}_{\mathrm{a} 1}$ is assumed as follows:

$\mathbf{H}_{\mathrm{a} 1}$ : There is significant difference in the level of computer literacy among professionals working in hospitals that have adopted the electronic healthcare system and those that work in hospitals that use the manual method of keeping records.

The chi square test statistics is computed as:

$$
\chi^{2}=\frac{\sum_{i=1}^{r} \sum_{j=1}^{c}\left(O_{i j}-E_{i j}\right)^{2}}{E_{i j}}
$$


Table 4. Result for the chi square test for the level of computer literacy among professionals and the method adopted in the hospitals

\begin{tabular}{|l|l|l|l|l|}
\hline \multicolumn{1}{|c|}{ Category } & \multicolumn{1}{c|}{$\boldsymbol{O}_{i j}$} & \multicolumn{1}{c|}{$\boldsymbol{E}_{i j}$} & \multicolumn{1}{c|}{$\boldsymbol{O}_{i j}-\boldsymbol{E}_{i j}$} & $\left(\boldsymbol{O}_{i j}-\boldsymbol{E}_{i j}\right)^{2} / \boldsymbol{E}_{i j}$ \\
\hline Row 1, Column 1 & 0 & 13.5 & -13.5 & 13.5 \\
\hline Row 1, Column 2 & 75 & 61.5 & 13.5 & 2.96 \\
\hline Row 2, Column 1 & 27 & 13.5 & 13.5 & 13.5 \\
\hline Row 2, Column 2 & 123 & 61.5 & 61.5 & 2.96 \\
\hline Total & & & & 32.93 \\
\hline
\end{tabular}

where $O_{i j}$ is the observed frequency in the $i^{\text {th }}$ row and $j^{\text {th }}$ column and $E_{i j}$ is the corresponding expected frequency. The chi square distribution has $(r-1)(c-1)$ degree of freedom where $r$ is the number of rows and $\mathrm{c}$ is the number of columns.

Table 4 provides the result for the chi square test.

The chi square test statistics is calculated as:

$\chi^{2}=13.5+2.96+13.5+2.96=32.93$

The chi square distribution is given as $\chi_{\alpha(2-1)(2-1)}^{2}=\chi_{0.05,1}^{2}=3.841$. The calculated chi square test statistics is 32.93. This value is greater than the chi square distribution table value of 3.841 . Hence, the alternative hypothesis will be accepted. Similarly, the R statistical package was also used to calculate the chi square test statistics. Again, the Chi-square test value gives a calculated value of 32.93 and a p-value of 0 which is less than the significant level of 0.05 . The test gives a significant result which indicates that there is significant difference in the level of computer literacy among professionals working in hospitals that have adopted the electronic healthcare style and those that work in hospitals that use the manual method of keeping records.

\subsection{Analysis on the Problems of Adopting the Electronic or Manual Method}

From the questionnaire, as earlier stated there are two key sections which are the problems of either adopting the electronic healthcare system or manual methods of keeping patient information and the efficiency, problems and barriers specific to adopting the electronic healthcare style in the hospitals.

Analysis to questions on the problems of either adopting the electronic healthcare system or manual methods of keeping patient information will be discussed whereas the efficiency, problems and barriers specific to the electronic style will be discussed in the following section. The responses from the respondents to the problems involved in the method used in hospital have been managed in five categories as "undecided (U)", "strongly disagreed (SD)", "disagree (D)", "agree (A)" and "strongly agree (SA)". The responses to data were translated for interpretation. The responses were allocated and scored with a numeric value from " 0 " to " 4 ". With these scores, a mean score is computed for each statement as shown in Table 5.

The arrangement in Table 5 shows that most of the professionals that work in hospitals that use the manual method of keeping patient records believe that improper documentation of patient records is a problem in the hospital while most of the professionals that work in hospitals where the electronic healthcare style is adopted strongly disagree or disagree that there is improper documentation in the 
Table 5. Summary of respondents to the problems of adopting the electronic or manual method in the hospitals

\begin{tabular}{|c|c|c|c|c|c|c|c|c|}
\hline Statements & Method & $\mathbf{U}$ & SD & $\mathbf{D}$ & A & SA & Total & Mean Score \\
\hline \multirow[t]{3}{*}{ Involves improper documentation of patient records. } & EHS & 10 & 26 & 39 & 0 & 0 & 75 & 1.39 \\
\hline & MANUAL & 0 & 1 & 16 & 41 & 17 & 75 & 2.99 \\
\hline & TOTAL & 10 & 27 & 55 & 41 & 17 & 150 & \\
\hline \multirow[t]{3}{*}{ Improper payment records } & EHS & 14 & 29 & 32 & 0 & 29 & 75 & 2.00 \\
\hline & MANUAL & 0 & 4 & 1 & 48 & 6 & 75 & 2.95 \\
\hline & TOTAL & 14 & 33 & 33 & 48 & 35 & 150 & \\
\hline \multirow[t]{3}{*}{ More time is required for data collection and entry. } & EHS & 9 & 36 & 10 & 13 & 7 & 75 & 1.64 \\
\hline & MANUAL & 0 & 0 & 0 & 17 & 58 & 75 & 3.77 \\
\hline & TOTAL & 9 & 36 & 10 & 30 & 65 & 150 & \\
\hline \multirow[t]{3}{*}{ Large space is occupied by heap of files } & EHS & 18 & 32 & 25 & 0 & 0 & 75 & 1.39 \\
\hline & MANUAL & 0 & 0 & 0 & 22 & 53 & 75 & 2.99 \\
\hline & TOTAL & 18 & 32 & 25 & 22 & 53 & 150 & \\
\hline \multirow[t]{3}{*}{ Difficulty in retrieving patient data } & EHS & 0 & 46 & 29 & 0 & 0 & 75 & 1.39 \\
\hline & MANUAL & 0 & 0 & 0 & 19 & 56 & 75 & 3.75 \\
\hline & TOTAL & 0 & 46 & 29 & 19 & 56 & 150 & \\
\hline \multirow[t]{3}{*}{ Much time wasted in retrieving data } & EHS & 0 & 48 & 27 & 0 & 0 & 75 & 1.36 \\
\hline & MANUAL & 0 & 0 & 0 & 17 & 58 & 75 & 3.77 \\
\hline & TOTAL & 0 & 48 & 27 & 17 & 58 & 150 & \\
\hline \multirow{3}{*}{$\begin{array}{l}\text { There is no confidentiality of the data and } \\
\text { information collected from the patient. }\end{array}$} & EHS & 5 & 41 & 29 & 0 & 0 & 75 & 1.32 \\
\hline & MANUAL & 0 & 4 & 4 & 21 & 46 & 75 & 3.45 \\
\hline & TOTAL & 5 & 45 & 33 & 21 & 46 & 150 & \\
\hline
\end{tabular}

hospital that use EHS. A mean score of 1.39 for EHS lies between strongly disagree and disagree but is closer to strongly disagree. With the exploratory analysis, it is possible to confirm that the professionals that work in hospitals where the electronic style is adopted strongly disagree that the hospitals which have adopted EHS have improperly documented records. Similarly, a mean score of 2.99 for professionals that work in hospitals that use the manual method of keeping patient records agree that the hospitals have improper documentation of records.

We can also summarize from Table 5 that most of the professionals that work in hospitals that use the manual method of keeping patient records agree (mean score of 2.95) that the hospitals have improper payment records, strongly agree (mean score of 3.77) that more time is required for data collection and data entry, agree (mean score of 2.99) that large space is occupied by heap of files, strongly agree (mean score of 3.75) that there is difficulty in retrieving patient data, strongly agree (mean score of 3.77) that much time is wasted in retrieving data and agree (mean score of 3.45) that there is no confidentiality of the data and information collected from the patient.

We can summarize from Table 5 that most of the professionals that work in hospitals that have adopted EHS strongly disagree (mean score of 1.39) that there is improper documentation of patient records, disagree (mean score of 2.00) that the hospitals have improper payment records, disagree (mean score of 1.64) that more time is required for data collection and data entry, strongly disagree (mean score of 1.39) that large space is occupied by heap of files, strongly disagree (mean score of 1.39) that there is difficulty in retrieving patient data, strongly disagree (mean score of 1.36) that 
much time is wasted in retrieving data and strongly disagree (mean score of 1.32) that there is no confidentiality of the data and information collected from the patient.

\subsection{Analysis on the Efficiency, Problems and Barriers Specific to the Electronic Healthcare Style}

Analysis to questions on the questionnaire on the efficiency, problems and barriers of the adoption of the electronic healthcare style (EHS) in the hospital is now discussed.

The responses from the respondents to the efficiency of the adoption of the EHS have been managed in five categories as "undecided", "strongly disagreed", "disagree", "agree" and "strongly agree". The responses to data were translated for interpretation. On the average, the professionals that work in hospitals that have adopted EHS agree (mean score of 3.03) that EHS has efficiently increased patient care, disagree (mean score of 2.09) that there is increase in the provision and management of hospital services, agree (mean score of 3.05) that EHS has efficiently increased interactivity in any area of specialization and agree (mean score of 3.24) that EHS has efficiently reduced medication administrative errors.

The responses from the respondents on the problems of adopting the EHS have also been managed in five categories as "undecided", "strongly disagreed", "disagree", "agree" and "strongly agree". The responses to data were translated for interpretation. On the average, the professionals that work in hospitals that have adopted EHS disagree (mean score of 1.75) that lack of belief of the adoption of electronic style in hospitals is a problem of EHS, agree (mean score of 3.15) that lack of continuous training support for Information Technology in hospital is a problem, agree (mean score of 3.19) that there is problem of hanging up of computer, strongly agree (mean score of 3.53) that the failure of electrical power is a problem and disagree (mean score of 2.28) that the crashing of computer is a problem of EHS.

The responses from the respondents on the barriers to the adoption and use of the EHS have again been managed in four categories as "not a barrier", "mini barrier", "moderate barrier" and "major barrier". The responses were allocated and scored with a numeric value from " 0 " to " 3 ". The responses to data were translated for interpretation. On the average, the professionals that work in hospitals that have adopted EHS believe (mean score of 2.53) that the requirement of huge amount of money to implement the system is a major barrier, resistance from staff is not a barrier (mean score of 0.44), lack of IT personnel and expertise within the organization is a moderate barrier (mean score of 2.34), the difficulty in transmitting historic information into new systems is a major barrier (mean score of 2.70), finding a system that meets the needs of users in your organization is a mini barrier (mean score of 1.67), software incompatibilities is a moderate barrier (mean score of 2.07), hardware incompatibilities is a moderate barrier (mean score of 2.16) and the difficulty obtaining or maintaining wireless access is a major barrier (mean score of 2.53).

\section{CONCLUSION, LIMITATIONS AND FUTURE WORK}

In this paper, how to enhance health care delivery through an electronic healthcare style is illustrated. The data collected from the questionnaires led to the analysis of two key measures, which are the problems of either adopting the electronic healthcare system or manual methods of keeping patient information and the efficiency, problems and barriers specific to adopting the electronic healthcare style in hospital services.

All professionals that work in hospitals that have adopted the electronic healthcare system are all computer literate. All Doctors were computer literate. Some of the professionals that work in hospitals that use the manual method of keeping patient records were not computer literate. The Chi - square test gives a significant result which indicated that there is significant difference in the level of computer literacy among professionals working in hospitals that have adopted the electronic healthcare system and those that work in hospitals that use the manual method of keeping records. 
It is obvious that improper documentation of patient records, improper payment records, large space being occupied by heap of files, difficulty in retrieving patient data, much time being wasted in retrieving data and no confidentiality of the data and information collected from the patient are problems of the hospitals that use the manual method of keeping records. Professionals that work in hospitals that adopted EHS do not believe that any of these problems are associated with their hospitals.

The professionals that work in hospitals that have adopted EHS believe that there is increased efficiency in patient care, interactivity in any area of specialization and reduction of medication administrative errors but do not believe that the provision and management of hospital services has improved. The professionals that work in hospitals that have adopted EHS believe that the problems of adopting EHS are lack of continuous training support for Information Technology in hospital, hanging of computer, failure of electrical power and crashing of computer. The professionals that work in hospitals that have adopted EHS also believe that there is the requirement of huge amount of money to implement the system, the difficulty in transmitting historic information into new systems and the difficulty obtaining or maintaining wireless access are major barriers. The lack of IT personnel and expertise within the organization, software and hardware incompatibilities are moderate barriers. The resistance of staff is not a barrier while finding a system that meets the needs of the users in the organization is a mini barrier.

The barriers mentioned can be resolved; for instance, loan facilities can be made available by the authorities to resolve the requirement of huge amount of money to implement the system. Facilitating training for the users and possible recruitment of qualified staff who are ICT compliant can resolve the difficulty in transmitting historic information into new systems and the lack of IT personnel and expertise within the organization. The provision of a workable wireless networking system could resolve the problem of the difficulty in obtaining or maintaining wireless access. Also, the establishment of ICT department that would be saddled with responsibility of making hardware and software systems compatible for the users all the time would resolve the software and hardware incompatibilities needs of the users in the organization.

The essence of evaluating the performance of adopting the electronic style in hospital services is to guarantee easy documentation and patients and professionals management in hospital services. The major contributions of this style are that data confidentiality and proper documentation are guaranteed and very little time is required for retrieving information. There is an improved interactivity in all areas of specialization using the EHS. Some barriers blocking the use of electronic healthcare system from widespread acceptance should be taken care of, and in the future there should be continuous training support for information technology (IT), supply of power and loans or financial assistance be given to implement the EHS.

This research used real data from clinical staff rather than simulated data which would provide us with more accurate results and hence, our research provides performance evaluation of EHR with meaningful results. Without the support of clinical staff, the adoption and use of electronic style would greatly suffer. In regards to the perspective of the patients; the assessment of the satisfaction of patients and opinion on the quality of service provided on the overall healthcare is not covered by this research. Positive satisfaction of patients will ensure wider adoption of the electronic style since patients and their data form the key attributes in the system. Another limitation is that it has not performed the evaluation of the implementation of the communication of medical data between different locations, that is, cross country or border. This will require the system to account for greater number of data.

There is the need to conduct further evaluation on the assessment of the satisfaction of patients and opinion on the quality of service provided on the overall healthcare. There is also the need to conduct the evaluation of the implementation of the communication of medical data between different locations, which is cross country or border. 


\section{REFERENCES}

Aceto, G., Persico, V., \& Pescapè, A. (2018). The role of Information and Communication Technologies in Healthcare: Taxonomies, Perspectives, and Challenges. Journal of Network and Computer Applications, 107, 125-154. doi:10.1016/j.jnca.2018.02.008

Alotaibi, Y. K., \& Federico, F. (2017). The impact of health information technology on patient safety. Saudi Medical Journal, 38(12), 1173-1180. doi:10.15537/smj.2017.12.20631 PMID:29209664

Alrasheed, A., Atkins, A. S., \& Campion, R. (2016). Performance improvement in hospital management using RFID and Zigbee technologies for tracking and monitoring patients and assets in Saudi Arabia. Proceedings of IIER 64th International Conference on Science, Innovation and Management (ICSIM). https://www.researchgate. net/publication/305142841

Boonstra, A., Versluis, A., \& Vos, J. F. J. (2014). Implementing electronic health records in hospitals: A systematic literature review. BMC Health Services Research, 14(1), 370. doi:10.1186/1472-6963-14-370 PMID:25190184

Chung, C., Patel, S., Lee, R., Fu, L., Reilly, S., Ho, T., Lionetti, J., George, M. D., \& Taylor, P. (2018). Implementation of an integrated computerized prescriber order-entry system for chemotherapy in a multisite safety-net health system. American Journal of Health-System Pharmacy, 75(6), 398-406. doi:10.2146/ajhp170251 PMID:29523537

Dash, S., Shakyawar, S. K., Sharma, M., \& Kaushik, S. (2019). Big data in healthcare: Management, analysis and future prospects. Journal of Big Data, 6(1), 54. doi:10.1186/s40537-019-0217-0

Dwenger, A. T., Fox, E. R., Macdonald, E. A., \& Edvalson, B. J. (2019). Implementation of hyperlinks to medication management policies and guidelines in the electronic health record. American Journal of HealthSystem Pharmacy, 76(3), 69-73. doi:10.1093/ajhp/zxz122 PMID:31352489

Evans, R. S. (n.d.). Electronic Health Records: Then, Now, and in the Future. https://www.thieme-connect.com/ products/ejournals/pdf/10.15265/IYS-2016-s006.pdf

Han, J. E., Rabinovich, M., Abraham, P., Satyanarayana, P., Liao, T. V., Udoji, T. N., Cotsonis, G. A., Honig, E. G., \& Martin, G. S. (2016). Effect of Electronic Health Record Implementation in Critical Care on Survival and Medication Errors. The American Journal of the Medical Sciences, 351(6), 576-581. doi:10.1016/j. amjms.2016.01.026 PMID:27238919

Iroju, O. G., \& Olaleke, J. O. (2015). Ethical issues in interoperability of electronic healthcare systems. Communications on Applied Electronic (CAE). www.caeacess.org

Kelley, T., Docherty, S., \& Brandon, D. (2013). Information needed to support knowing the patient. Advances in Nursing Science, 36(4), 351-363. doi:10.1097/ANS.0000000000000006 PMID:24169113

Kruse, C. S., Stein, A., Thomas, H., \& Kaur, H. (2018). The use of Electronic Health Records to Support Population Health: A Systematic Review of the Literature. Journal of Medical Systems, 42(11), 1-16. doi:10.1007/ s10916-018-1075-6 PMID:30269237

Land, T. F. (2019). Communication: The Driving Force for Better Outcomes. Frontiers of Health Services Management, 36(1), 1-2. doi:10.1097/HAP.0000000000000065 PMID:31449065

Lichtner, V., Franklin, B. D., Dalla-Pozza, L., \& Westbrook, J. I. (2020). Electronic ordering and the management of treatment interdependencies: A qualitative study of paediatric chemotherapy. BMC Medical Informatics and Decision Making, 20(193). Advance online publication. doi:10.1186/s12911-020-01212-z PMID:32795356

Liu, Q., Luo, D., Haase, J. E., Guo, Q., Wang, X. Q., Liu, S., Xia, L., Liu, Z., Yang, J., \& Yang, B. X. (2020). The experiences of health-care providers during the COVID-19 crisis in China: A qualitative study. The Lancet. Global Health, 8(6), 790-798. doi:10.1016/S2214-109X(20)30204-7 PMID:32573443

Loo, S., Grasso, C., Glushkina, J., McReynolds, J., Lober, W., Crane, H., \& Mayer, K. H. (2020). Capturing relevant patient data in clinical encounters through integration of an electronic patient-reported outcome system into routine primary care in a Boston community health center: Development and implementation study. Journal of Medical Internet Research, 22(8), e16778. doi:10.2196/16778 PMID:32554372 
Mardiah, F. P., \& Basri, M. H. (2013). The analysis of appointment system to reduce outpatient waiting time at In donesia's public hospital. Human Resource Management Review, 3(1), 27-33.

Metahri, D., \& Hachemi, K. (2020). A performance comparison of manual dispensing and automated drug delivery. International Journal of Applied Research on Public Health Management, 5(1), 1-13. doi:10.4018/ IJARPHM.2020010101

Mitchell, M., \& Kan, L. (2019). Digital technology and the future of health systems. Health Systems and Reform, 5(2), 113-120. doi:10.1080/23288604.2019.1583040 PMID:30908111

Mohd, N. A., \& Muhammad, A. (2012). Health Information Systems (HIS), Concept and Technology. Universiti Brunei Darussalam. www.researchgate.net/publication/221710863

Nduka, E. C. (2015). Statistics concepts and methods, Clara's Prints. Rivers State.

Ondieki, F. (2017). Effects of Health Records Management on Service Delivery: A Case Study of Kisii Teaching and Referral Hospital. Journal of Hospital Medical Management, 3(1), 1-5.

Pardamean, B., Louis, S., \& Setyaningrum, L. (2012). Designing Medical Checkup Information System for the Navy Hospitals. International Journal of Biology and Biomedical Engineering, 1(6), 1-10.

Parsons, A., \& James, E. F. (2019). Addressing workforce challenges in healthcare calls for proactive leadership. Frontiers of Health Services Management, 35(4), 11-17. doi:10.1097/HAP.0000000000000058

Liu, Q., Luo, D., Haase, J. E., Guo, Q., Wang, X. Q., Liu, S., Xia, L., Liu, Z., Yang, J., \& Yang, B. X. (2020). The experiences of health-care providers during the COVID-19 crisis in China: A qualitative study. The Lancet. Global Health, 8(6), 790-798. doi:10.1016/S2214-109X(20)30204-7 PMID:32573443

Ratwani, R. M., Savage, E., Will, A., Fong, A., Karavite, D., Muthu, N., Rivera, A. J., Gibson, C., Asmonga, D., Moscovitch, B., Grundmeier, R., \& Rising, J. (2018). Identifying Electronic Health Record Usability And Safety Challenges In Pediatric Settings. Health Affairs (Project Hope), 37(11), 1752-1759. doi:10.1377/ hlthaff.2018.0699 PMID:30395517

Reis, Z. S. N., Maia, T. A., Marcolino, M. S., Becerra-Posada, F., Novillo-Ortiz, D., \& Ribeiro, A. L. P. (2017). Is there evidence of cost benefits of electronic medical records, standards, or interoperability in hospital information systems? Overview of systematic reviews. JMIR Medical Informatics, 5(3), e26. doi:10.2196/medinform.7400 PMID:28851681

R Development Core Team. (n.d.). R: A language and Environment of statistical computing. Vienna, Austria: Author.

Reisman, M. (2017). EHRs: The challenge of making electronic data usable and interoperable. Pharmacology \& Therapeutics, 42(9), 572-575. PMID:28890644

Ross, J., Stevenson, F., Lau, R., \& Murray, E. (2016). Factors that influence the implementation of e-health: A systematic review of systematic reviews (an update). Implementation Science; IS, 11(1), 146. doi:10.1186/ s13012-016-0510-7 PMID:27782832

Rotenstein, L. S., Huckman, R. S., \& Wagle, N. W. (2017). Making patients and doctors happier - The potential of patient-reported outcomes. The New England Journal of Medicine, 377(14), 1309-1312. doi:10.1056/ NEJMp1707537 PMID:28976860

Sanam, R.-D. (2020). Health System Quality in the time of Covid-19. The Lancet. Global Health, 8(6), 738-739. doi:10.1016/S2214-109X(20)30223-0 PMID:32389194

Sarkies, M. N., Bowles, K. A., Skinner, E. H., Mitchell, D., Haas, R., Ho, M., Salter, K., May, K., Markham, D., O'Brien, L., Plumb, S., \& Haines, T. P. (2015). Data collection methods in health services research: Hospital length of stay and discharge destination. Applied Clinical Informatics, 6(1), 96-109. doi:10.4338/ACI-201410-RA-0097 PMID:25848416

Schopf, T. R., Nedrebø, B., Hufthammer, K. O., Daphu, I. K., \& Lærum, H. (2019). How well is the electronic health record supporting the clinical tasks of hospital physicians? A survey of physicians at three Norwegian hospitals. BMC Health Services Research, 19(1), 934. doi:10.1186/s12913-019-4763-0 PMID:31801518 
Sieck, C. J., Pearl, N., Bright, T. J., \& Yen, P. (2020). A qualitative study of physician perspectives on adaptation to electronic health records. BMC Medical Informatics and Decision Making, 20(25), 1-8. doi:10.1186/s12911020-1030-6 PMID:32039728

Venkatesh, V., Zhang, X., \& Sykes, T. (2011). "Doctors do too little technology": A longitudinal field study of an electronic healthcare system implementation. Information Systems Research, 22(3), 523-546. doi:10.1287/ isre. 1110.0383

Wang, C. (2020). Exploring health information exchange through a system of systems framework. International Journal of Applied Research on Public Health Management, 5(2), 1-12. doi:10.4018/IJARPHM.2020070101

Williams, M. D. (2018). The Impact of Organizational Culture on Leadership Burnout. Frontiers of Health Services Management, 35(2), 34-37. doi:10.1097/HAP.0000000000000047 PMID:30433903

Whalen, K., Lynch, E., Moawad, I., John, T., Lozowski, D., \& Cummings, B. M. (2018). Transition to a new electronic health record and pediatric medication safety: Lessons learned in pediatrics within a large academic health system. Journal of the American Medical Informatics Association, 25(7), 848-854. doi:10.1093/jamia/ ocy034 PMID:29688461

Juliana Iworikumo Consul has a PhD in Statistics from Newcastle University, UK. She is currently a Senior Lecturer in the Department of Mathematics, Niger Delta University, Bayelsa State, Nigeria.

Bunakiye Richard Japheth has a PhD in Computer Science from University of Port Harcourt, Nigeria. He is currently a Senior Lecturer in the Department of Computer Science, Niger Delta University, Bayelsa State, Nigeria. His main research work focuses on Requirements Engineering, Domain Specific Modelling, Theory of Computation, Formal Specification and Verification, and Cybersecurity. He has 12 years of teaching experience and 10 years of Research Experience.

Joseph Agaroghenefuoma Erho is currently a Lecturer in the Department of Computer Science, Niger Delta University, Bayelsa State, Nigeria. 